\title{
Estudo experimental do poliuretano de óleo de mamona (Ricinus communis) como substituto parcial do tendão calcâneo comum em coelhos (Oryctolagus cuniculus)
}

[An experimental study of polyurethane of castor-oil plant (Ricinus communis) as a partial substitute of the common calcaneous tendon in rabbits (Oryctogalus cuniculus)]

\author{
C.M.F. Rezende ${ }^{1}$, M.C. Silva ${ }^{2}$, M.G. Laranjeira ${ }^{3}$, A.P.B Borges ${ }^{4}$ \\ ${ }^{1}$ Escola de Veterinária da Universidade Federal de Minas Gerais \\ ${ }^{2 *}$ Faculdade de Veterinária da Universidade Estadual do Ceará \\ Av. Paranjana, 1700. Campus Itaperi \\ 60170-000 - Fortaleza, CE \\ ${ }^{3}$ Curso de Medicina Veterinária. FOA. UNESP. Araçatuba \\ ${ }^{4}$ Departamento de Veterinária da Universidade Federal de Viçosa
}

Recebido para publicação em 16 de agosto de 2000.

Recebido para publicação, após modificações, em 7 de agosto de 2001

*Autor para correspondência

E-mail: mariacristina.silva@bol.com.br

\section{RESUMO}

Com o objetivo de avaliar a eficiência da prótese de poliuretano de mamona como substituto parcial do tendão calcâneo comum, foram utilizadas 30 coelhas da raça Nova Zelândia, entre dois e três meses de idade e peso médio de $2 \mathrm{~kg}$. Após anestesia geral, o procedimento cirúrgico em ambos os membros constou de incisão caudo-lateral no sentido longitudinal do terço médio ao distal da tíbia e exposição do tendão calcâneo comum. Após a tenectomia do tendão do músculo gastrocnêmio, a prótese de poliuretano de cerca de $0,5 \mathrm{~cm}$ de extensão por $0,5 \mathrm{~cm}$ de diâmetro foi fixada aos cotos proximal e distal do tendão, empregando-se o fio de polipropileno monofilamentar 4-0, conforme técnica modificada de Kessler. A prótese de poliuretano na forma elastomérica revelou propriedades como textura e flexibilidade semelhantes à do tecido tendinoso, pode ser confeccionada na forma e no tamanho almejados e permite ser moldada, cortada e esterilizada por calor úmido. Todos os animais apoiaram os membros operados imediatamente após o retorno anestésico. Não se observaram sinais clínicos de infecção e não ocorreu deiscência de ferida. Percebeu-se aumento de volume local devido ao edema, evidente na primeira semana pós-cirúrgica, que gradualmente desapareceu . À palpação foi possível delimitar com facilidade a prótese que se conservou fixa no local e intacta. Clinicamente o poliuretano de mamona não induziu reação desfavorável que comprometesse a cicatrização tendínea, podendo ser indicado como substituto temporário de tendão.

Palavras-chave: Coelho, cirurgia, prótese, poliuretano, tendão

\begin{abstract}
With the goal of evaluating the efficiency of a prosthesis of castor-oil plant (Ricinus communis) polyurethane as a partial substitute for common calcaneous tendon, 30 New Zealand female rabbits, aging between two to three months, weighting about $2 \mathrm{~kg}$ were used. After general anesthesia, the surgical procedure in both members consisted of rear lateral longitudinal incision, in the medium third of the distal of tibia and exposition of the common calcaneous tendon. After the tenectomies of the gastrocnemius muscle tendon, the polyurethane prosthesis of about $0,5 \mathrm{~cm}$ in length by 0,5 in diameter
\end{abstract}


was seized to the proximal and distal of the tendon stumps, using polypropylene 4-0 suture just like the Keessler modified technique. The prosthesis of polyurethane in the form of elastomers revealed qualities like the texture and flexibility similar to the tendon tissue, and it can be made in the form and size desired. In addition, it can be shaped, cut and sterilized in wet heat. All animals could stand on the surgically treated members immediately after the end of anesthetic effect. No clinical signs of infection and no dehiscence of the cut were observed. An increase of local volume, due to the edema, evident in the first week after the surgery could be noted, which gradually disappeared. It was possible to detect easily upon touch the prosthesis which remained fixed in place. Clinically, the polyurethane of castoroil plant did not induce any unfavorable reaction which could compromise the tendon healing and can be indicated as a temporary substitute of a tendon.

Keywords: Rabbit, surgery, prothesis, polyurethane, tendon

\section{INTRODUÇÃO}

Os traumatismos de tendões são problemas ortopédicos relativamente freqüentes, especialmente em animais de corrida como cavalos e cães da raça Greyhound. Outras lesões tendinosas importantes envolvem a secção parcial ou total por objetos cortantes ou lacerações associadas a acidentes automobilísticos. A secção do tendão calcâneo comum ou dos flexores digitais leva a alteração postural grave que poderá ser de difícil correção, não sendo incomum nas espécies canina (Vaughan, 1980; Bonneau et al., 1983), eqüina (Goodship, 1993) e humana (Nystrom \& Holmlund, 1983). A substituição do tendão torna-se necessária especialmente quando há perda de parte do tecido e, nesses casos, o enxerto ou a prótese fornecem suporte e orientação para a migração de células e formação de fibras (Valdés-Vásquez et al., 1996). Ocasionalmente tendões devem ser alongados ou encurtados devido a defeito de conformação, desenvolvimento inadequado ou por complicações de tratamentos de feridas que envolvem essas estruturas (Clark, 1993).

Os vários métodos de tratamento de lesões tendinosas refletem a necessidade de uma técnica que permita o retorno morfológico e funcional do tendão (Goodship et al., 1985). Na tentativa de contornar problemas diversos como antigenicidade, estocagem e disponibilidade de implantes, têm-se desenvolvido os chamados biomateriais para substituição de tecidos. Nas duas últimas décadas a pesquisa de biopolímeros tem se intensificado, sendo grande a contribuição nas áreas de implantes cardiovalvulares, odontológicos, ópticos e neurocirúrgicos (Ohara et al., 1995).

O desenvolvimento dos polímeros como biomateriais tem contribuído para o sucesso de implantes nos tecidos moles, pois além da biocompatibilidade podem ser confeccionados sob medida, adaptando-se às propriedades dos tecidos. Adicionalmente, os polímeros podem ter forma física variada, como líquida para preencher espaço, fibra para materiais de sutura, filme (cateter inflável) e sólida para aplicações cosmética e mecânica (Park \& Lakes, 1992).

A descoberta de novos polímeros e copolímeros tem contribuído significativamente para a evolução do campo dos biomateriais. Em 1984, o grupo de química analítica e tecnologia de polímeros do Instituto de Química de São Carlos da Universidade de São Paulo desenvolveu um novo poliol derivado do óleo da mamona (Ignácio, 1995). A mamona (Ricinus communis) da classe dicotiledônea, origem Geraniácea, família Euforbaceaes, é uma planta característica de clima tropical, possui grande potencial oleoquímico, podendo garantir o fornecimento de polióis e pré-polímeros a partir de ácidos graxos (Ohara et al., 1995). Essas características levaram os pesquisadores a investigarem a viabilidade do emprego desses polímeros na área biológica. 
Estudo experimental do poliuretano de óleo de mamona...

Estudos da biocompatibilidade de polímeros de poliuretano derivados do óleo da mamona revelam um produto biocompatível, atóxico e com baixíssima hidrofilia, que permite inclusive a regeneração e incorporação de tecidos orgânicos. Esse poliuretano possui fórmula molecular que além de biocompatibilidade apresenta aspectos favoráveis quanto à processabilidade, flexibilidade de formulação, versatilidade de temperatura de curva e controle de pico exotérmico na transição líquido-gel, possui excelentes propriedades estruturais, não emite vapores tóxicos, tem bom poder de adesão, não libera radicais tóxicos quando implantado e é de baixo custo (Ignácio, 1995).

As vantagens apresentadas pelos polímeros de poliuretano possibilitam ampla variedade de aplicações médicas, destacando-se principalmente suas texturas variáveis, desde as mais flexíveis, como a dos elastômeros, até as mais rígidas, como a dos cimentos ósseos (Viana, 1997).

Este trabalho teve por objetivo avaliar o emprego da prótese de poliuretano, derivado do óleo de mamona, como substituto de tendão, na correção de secção parcial do tendão calcâneo comum de coelho.

\section{MATERIAL E MÉTODO}

Foram utilizadas 30 coelhas clinicamente sadias da raça Nova Zelândia, com média de peso de $2 \mathrm{~kg}$, idade entre dois e três meses, adquiridas junto à Fazenda Experimental Prof. Hélio Barbosa da Escola de Veterinária da UFMG.

Os animais alojados em gaiolas individuais receberam ração comercial uma vez ao dia e água à vontade. Antes da cirurgia houve um período de adaptação ao novo ambiente com duração de sete dias. Todos os animais foram submetidos ao mesmo tratamento cirúrgico. As avaliações foram feitas diariamente na primeira semana e 2, 3, 6, 16 e 28 semanas após a cirurgia.

A prótese foi elaborada no laboratório de química analítica e tecnologia de polímeros do Instituto de Química de São Carlos da Universidade de São Paulo.

Para a confecção da prótese foi desenvolvida uma poliuretana elastomérica, obtida pela polimerização do poliol e do pré-polímero, derivados do óleo de mamona e de isocianatos. Os produtos foram misturados na proporção 1,8:1, cuidadosamente homogeneizados e mantidos sob vácuo para eliminação de bolhas. Ao final desse processo, a mistura foi introduzida em tubos de plástico de $0,5 \mathrm{~cm}$ de diâmetro, onde permaneceu por no mínimo 24 horas. Depois disso, a prótese foi removida, mantida em meio ambiente e encaminhada para esterilização em autoclave a $120-130^{\circ} \mathrm{C}$, sob 1,5 atmosferas de pressão, durante 60 minutos.

Os coelhos foram submetidos à tricotomia dos membros pélvicos e do abdome 24 horas antes da cirurgia e ao jejum alimentar de 12 horas. O protocolo anestésico adotado consistiu de pré-medicação com ketamina (Ketalar - Wellcome) $(30 \mathrm{mg} / \mathrm{kg}$ ) e xilazina (Rompum $2 \%$ - Bayer S.A.) $(5,0 \mathrm{mg} / \mathrm{kg})$, via intramuscular, seguida, 15min. após, de indução anestésica e manutenção por inalação espontânea da mistura halotanooxigênio (Fluothane - ZENECA Farmacêutica do Brasil Ltda) em circuito semi-fechado. Realizou-se antibioticoterapia profilática com administração de cefalotina sódica (Cefalotina - Glaxo do Brasil S.A.) $(15 \mathrm{mg} / \mathrm{kg})$, via intramuscular, 30min antes da incisão na pele.

Após a preparação asséptica de rotina e posicionamento dos animais em decúbito lateral direito, pele e tecido subcutâneo de ambos os membros posteriores foram incisados caudo-lateralmente no sentido longitudinal, do terço médio ao distal da tíbia. Após a exposição do tendão calcâneo comum, o tendão do músculo gastrocnêmio foi individualizado e seccionado transversalmente, removendo-se um fragmento de cerca de $0,3 \mathrm{~cm}$ de extensão. A seguir, fez-se a sutura da prótese de poliuretano de $0,5 \mathrm{~cm}$ de extensão no local com fio polipropileno (Prolene - ETHICON - Johnson \& Johnson) monofilamentar 4-0 agulhado, 
conforme a técnica modificada de Kessler (Aron,1981), ilustrada na Fig. 1. A prótese foi fixada por sutura, preenchendo a falha tendínea. A sutura iniciou-se na extremidade distal da prótese passando-se o fio através dela (1) até o tendão receptor (2 e 3), retornando através do tendão receptor (4) e da prótese (5) e passando pela extremidade distal do tendão (6,7 e 8), permanecendo o nó envolvido pelo tendão e prótese. As alças da sutura foram feitas no tendão receptor. A pele foi suturada com mononáilon 3-0 agulhado. Durante a cirurgia os tecidos incisados foram irrigados com solução isotônica de cloreto de sódio. A ferida cirúrgica foi protegida com atadura de crepom até o $10^{\circ}$ dia, quando ocorreu a remoção da sutura de pele.

O exame clínico diário constou de observação do estado geral do animal e da ferida cirúrgica, avaliandose a presença ou não de sinais flogísticos e de secreção.
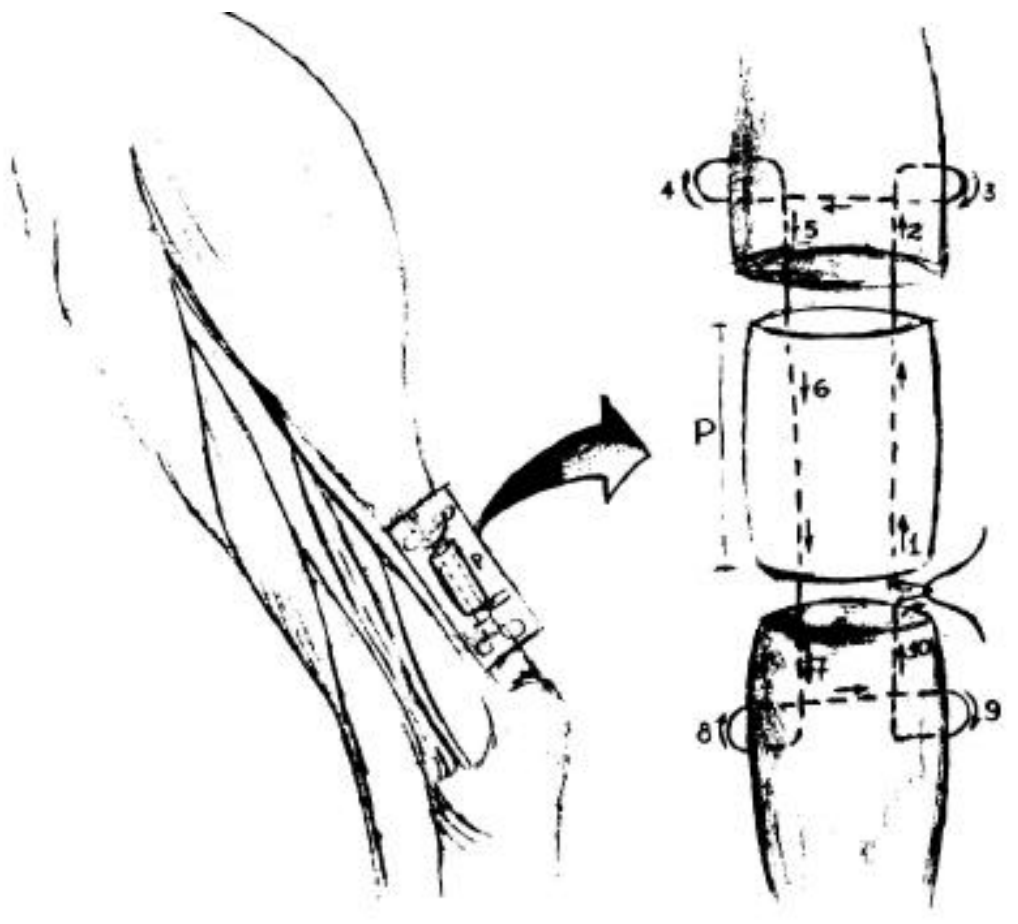

Figura 1. Representação esquemática da sutura modificada de Kessler adaptada à prótese(p) de poliuretano. Os números correspondem à sequiência de introdução da agulha e as setas ilustram a direção.

\section{RESULTADOS E DISCUSSÃO}

O interesse por implantes tendinosos sintéticos vem de longa data, pois já no início do século Biesalski (1910), citado por Urbaniak et al. (1974), propôs o uso de tubos de celulóide que evoluiu mais recentemente para o uso de próteses, como indicado por Hunter \& Salisbury (1970), Kato et al. (1991) e Hunter et al. (1995). A inovação proposta neste trabalho refere-se ao tipo de material empregado, desenvolvido a partir de polióis e pré-polímeros derivados do óleo da mamona (Ricinus comunis). A poliuretana desenvolvida a partir desse óleo é um composto com características químicas e físicas versáteis, que permitem diferentes aplicações na área biomédica. Pesquisas preliminares da 
biocompatibilidade demonstraram ausência de reações tóxicas e de rejeição do produto quando implantado no organismo vivo (Ohara et al., 1995), mas a continuidade dos estudos se faz necessária para avaliações mais detalhadas de sua aplicabilidade.

Neste experimento foi adotada a secção parcial do tendão calcâneo comum como modelo experimental por ser de fácil execução e reduzir eventuais transtornos relacionados com a não imobilização da articulação tíbio-társica, sem comprometer a avaliação da resposta tecidual ao implante. O protocolo pré-anestésico empregado proporcionou o miorrelaxamento e a contenção necessários para a manipulação e a indução anestésica com máscara. O emprego da anestesia geral volátil foi motivado por ser mais segura e propiciar analgesia adequada para manipulação dos tecidos, permitindo mais segurança na realização da sutura. O retorno anestésico ocorreu de maneira tranqüila, o que evitou ocorrência de eventuais complicações cirúrgicas no pós-operatório imediato. Nenhum dos animais apresentou características cárdio-respiratórias abaixo dos limites mínimos e o tempo de anestesia foi de aproximadamente uma hora.

A prótese de poliuretana mostrou-se de fácil manipulação permitindo ser moldada, cortada e esterilizada sem dificuldades. A esterilização por calor úmido não provocou mudança na cor, na textura e, aparentemente, na resistência do polímero. A prótese de cerca de $0,3 \mathrm{~cm}$ de diâmetro por $0,5 \mathrm{~cm}$ de extensão permitiu a passagem por duas vezes do fio polipropileno monofilamentar agulhado $\mathrm{n}^{\circ} 4-0$, que a fixou às extremidades seccionadas do tendão do músculo gastrocnêmio. $\mathrm{O}$ manuseio da prótese durante $\mathrm{o}$ procedimento cirúrgico foi relativamente fácil. A agulha de sutura foi modificada da forma semicircular para a reta para facilitar a síntese e manter a integridade da prótese, uma vez que o polímero mostrou-se susceptível à superfície cortante.

Sob o ponto de vista clínico, aparentemente a prótese de mamona na forma elastomérica revelou propriedades semelhantes à do tecido tendinoso, especialmente quanto à textura e flexibilidade, preenchendo alguns requisitos para implantes em tecido mole, conforme Park \& Lakes (1992). Além disso, pode ser confeccionada sob medida na forma e no tamanho almejados, o que é uma característica notória dos polímeros (Askeland, 1996; Viana, 1997). Entretanto, no que se refere à resistência, apesar de não se ter realizado ensaios mecânicos na prótese, observou-se que ela rompia facilmente à tração manual.

É sabido que o comportamento mecânico é uma das principais características de um biomaterial, sendo de conhecimento da comunidade científica que a força de resistência à ruptura dos poliuretanos elastoméricos puros é pequena. A adição de fios de poliéster à prótese para aumentar a resistência mecânica, como sugerido por Fonseca (1997), não foi empregada neste experimento, pois o objetivo era avaliar o comportamento da prótese na forma elastomérica pura. Além do mais, os fios de sutura são considerados também um substituto de tendão.

Todos os coelhos apoiaram os membros operados imediatamente após o retorno anestésico e mantiveram a postura natural pertinente à espécie. Houve evolução clínica normal, não se observando sinais de infecção. A cicatrização cutânea ocorreu por primeira intenção e, apesar dos membros operados estarem envolvidos por ataduras até a retirada dos pontos, permaneceu intacta, sem indícios de incompatibilidade e desconforto suficientes para que o animal interferisse no curativo. A ocorrência de deiscência de ferida poderia ser esperada no período pós-operatório, em consequiência da presença de corpo estranho ou de infecção. Entretanto, nesta pesquisa os resultados clínicos sugerem compatibilidade do implante, uma vez que as feridas cirúrgicas apresentaram apenas o edema esperado conseqüente à manipulação dos tecidos. Ausência de reações do tipo corpo estranho ou de rejeição foi citada por Ohara et al. (1995) após o emprego de resina de mamona intra-óssea e intra-articular em coelhos, não sendo verificada qualquer alteração do estado geral ou da função do membro operado. Portanto, do ponto de vista clínico-cirúrgico, também neste trabalho o uso da prótese se mostrou favorável. 


\section{Rezende et al.}

Nos animais examinados uma semana após a cirurgia o aumento de volume local devido ao edema foi mais evidente, dificultando a individualização da prótese à palpação. Após a segunda e terceira semanas de pós-operatório observou-se regressão do edema, não mais observado nos períodos subseqüentes. Foi possível, portanto, delimitar com facilidade a prótese que aparentemente conservou-se intacta e fixa no local. Pelo fato de a prótese permanecer aparentemente sem alterações e como o aumento de volume desapareceu assim que cessou a resposta inflamatória, pode-se dizer que clinicamente a prótese não induziu reação desfavorável, não comprometendo a cicatrização tendínea.

\section{CONCLUSÕES}

Nas condições em que foi realizado este experimento pode-se concluir que a prótese de poliuretano de mamona é clinicamente biocompatível, permite ser moldada, fabricada sob medida e esterilizada pelo calor úmido, e ser indicada como implante temporário de tendão em coelhos.

\section{REFERÊNCIAS BIBLIOGRÁFICAS}

ARON, D.N. A “New” tendon stitch. J. Am. Anim. Hosp. Assoc., v.17, p.587-591, 1981.

ASKELAND, D.R. Introduction to materials. In:__. The science and engineering of materials. 3. ed. London: Chapman \& Hall, 1996. p.3-15.

BONNEAU, N.H., OLIVIERI, M.O., BRETON, L.B. Avulsion of the gastrocnemius tendon in the dog causing flexion of the hock and digits. J. Am. Anim. Hosp. Assoc., v.19, p.717-722, 1983.

CLARK, D.M. Tendon injury and repair. In: BOJRAB, J.M. Disease mechanisms in small animal surgery. 2.ed. Lea \& Febiger, p.1079-1082, 1993.

FONSECA, M.C.R. Ensaio mecânico de tração de uma poliuretana elastomérica derivada do óleo da mamona para uso como implante tendinoso. Ribeirão Preto: Faculdade de Medicina de Ribeirão Preto e Escola de Engenharia de São Carlos, USP, 1997, 84p. (Dissertação, Mestrado).

GOODSHIP, A.E. The pathophysiology of flexor tendon injury in the horse. Equine Vet. J., v.5, p.23-29, 1993.

GOODSHIP, A.E., WILCOCK, S.A., SHAH, J.S. The development of tissue around various prosthetic implants used as replacemente for ligaments and tendons. Clin. Orthopaed. Rel. Res., n.196, p.61-68, 1985.

HUNTER, J.M., SALISBURY, R.E. Use of gliding artificial implants to produce tendon sheaths. Plast. Reconst. Surg., v.45, p.564-572, 1970.

HUNTER, J.M., MACKIN, E. J., CALLAHAN, A.D. Staged flexor tendon reconstruction using passive and active implants. In: __. Rehabilitation of the hand: surgery and therapy. Pennsylvania: The C.V.Mosby Comp., 1995. p.477-514.

IGNÁCIO, H. Utilização do cimento derivado do polímero da mamona no preenchimento de falha óssea. Estudo experimental em coelhos. Ribeirão Preto: Faculdade de Medicina de Ribeirão Preto da USP, 1995. 96p. (Dissertação, Mestrado).

KATO, Y.P., DUNN, M.G., ZAWADSKY, J.P. et al. Regeneration of Achilles tendon with a collagen tendon prosthesis. J. Bone Joint Surg., v.73-A, p.561-574, 1991.

NYSTROM, B., HOLMLUND, D. Experimental evaluation of immobilization in operative and non-operative treatment of Achiles tendon. A radiographic study in the rabbit. Acta Chir. Scand.,v.149, p.669-673, 1983

OHARA, G.H., KOJIMA, K.E., ROSSI, J.C. et al. Estudo experimental da biocompatibilidade do polímero poliuretano da mamona implantada intra-óssea e intra-articular em coelhos. Acta Orthop. Bras., v.3, p.62-68, 1995.

PARK, J.B., LAKES, R.S. Tissue response to implants. In: Biomaterials. An introduction. 2 ed. New York and London: Plenum Press, 1992. p.223-244.

URBANIAK, J.R., BRIGHT, D.S., GILL, L.H et al. Vascularization and gliding mechanism of free flexor-tendon grafts inserted by the silicone-rod method. J. Bone Joint Surg., v.56, p.473-482. 1974.

VALDÉS-VÁSQUEZ, M.A., McCLURE, J.R., OLIVER III, J.L. et al. Evaluation of an autologous tendon graft repair method for gap healing of the deep digital flexor tendon in horses. Vet. Surg., v.25, p.342-350, 1996.

VAUGHAN, L.C. Tendon injuries in dogs. California Vet., v.1, p.15-19, 1980. 
Estudo experimental do poliuretano de óleo de mamona...

VIANA, D.L. Estudo comparativo da resistência mecânica da "poliuretana derivada do óleo da mamona", submetida a ensaios de tração. Ribeirão Preto: Faculdade de Medicina de Ribeirão Preto e Escola de Engenharia de São Carlos, USP, 1997, 70p. (Dissertação, Mestrado). 